\section{IMPLICAÇÖES DE ASPECTOS ETIOPATOGÊNICOS NO TRATAMENTO DA FOLIE À DEUX}

A folie à deuxfoi descrita por Lasègue e Falret, em I 877, como sendo um fenômeno no qual havia transferência de delírios de um indivíduo primariamente afetado (quadro primário) a um outro previamente saudável (quadro secundário), com quem este apresentava um convívio íntimo e restrito' . No entanto, o tratamento de tal transtorno, em especial no que tange à abordagem do paciente que apresenta o quadro secundário, ainda continua controverso. Assim, a melhor compreensão dos aspectos etiopatogênicos da folie à deux pode contribuir para a utilização de abordagens terapêuticas mais adequadas. Desse modo, a partir do presente relato, serão apresentados e discutidos aspectos da etiopatogenia do transtorno que podem influenciar na abordagem terapêutica dos pacientes.

Duas gêmeas monozigóticas, de 38 anos de idade, foram internadas após viverem, por oito anos, completamente isoladas em um sítio da família. Quando da internação, ambas estavam psicóticas, com delírios paranóides. Ambas não apresentavam alterações da sensopercepção ou do humor. Os exames laboratoriais e de neuroimagem não apresentavam alterações. Apresentavam história familiar para transtornos psicóticos. Foi feito o diagnóstico de transtorno delirante persistente para ambas. Como apresentavam compartilhamento dos delírios, preenchiam critério de folie à deux. No entanto, não foi possível identificar qual delas começou a apresentar primeiramente os sintomas psicóticos, já que viviam isoladas.

Estudos têm sugerido que os indivíduos que apresentam o quadro secundário na folie à deuxapresentam um caráter individual de suscetibilidade para o desenvolvimento de sintomas psicóticos, envolvendo a participação de um componente genético na sua etiopatogenia ${ }^{2-3}$. O componente ambiental nesses casos deve funcionar como fator desencadeante de um quadro psicótico em um indivíduo já previamente suscetível, que provavelmente apresentaria tal manifestação em algum momento de sua vida ${ }^{4}$. A folie à deux aparece em situações de convívio íntimo entre dois indivíduos ${ }^{5}$, sendo o isolamento social, associado ao contato prolongado, o seu principal fator de risco ambiental ${ }^{6-7}$. Tal compreensão da etiopatogenia da folie à deuxé extremamente importante, pois traz implicações diretas à sua abordagem terapêutica. Desse modo, um tratamento adequado na folie à deux deve abordartanto os aspectos biológicos como também os ambientais relacionados à sua etiopatogenia.

Como a folie à deux está relacionada ao desenvolvimento de sintomas psicóticos devido à convivência íntima, a separação dos indivíduos acometidos tem sido a abordagem terapêutica mais utilizada nessas situações ${ }^{6}$. Tal abordagem serve não só para o tratamento do indivíduo secundariamente acometido pelos sintomas psicóticos, mas também para o tratamento do paciente com o quadro psicopatológico primário, isso porque os indivíduos fornecem suporte mútuo um ao outro. No entanto, a simples separação dos indivíduos acometidos não deve ser utilizada isoladamente na abordagem terapêutica desses pacientes ${ }^{6}$. Assim, no relato apresentado, optou-se durante a internação das pacientes por separá-las em enfermarias diferentes, e introduzir o antipsicótico risperidona até a dose de $6 \mathrm{mg} /$ dia para ambas, mesmo não sabendo qual delas apresentava o quadro primário ou secundário. Com isso, após três meses de internação, as pacientes receberam alta com remissão completa dos sintomas psicóticos. Tais resultados corroboram a necessidade da abordagem terapêutica na folie à deuxlevando em consideração aspectos da etiopatogenia do transtorno.

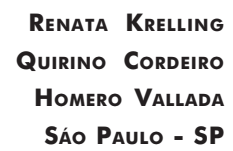

Referências

I. Lasègue C, Falret J. La folie à deux. Ann Med Psychol.| 877; 18:321. 2. Scharfetter C. Studies of heredity in symbiontic psychoses. Int J Ment Health. 1972; I: | |6-23.

3. Shiwach RS, Sobin PB. Monozygotic twins, folie à deux and herdability: a case report and critical review. Med Hypotheses. 1998;50:369-74.

4. Lazarus A. Folie a deux in identical twins: interaction of nature and nurture. Br J Psychiatry. 1986; |48:324-6.

5. Chapman AH, Vieira e Silva D. Folie a deux dissociative disorder in prepubertal children. Report of two cases with EEGs. Arq Neuropsiquiatr. 1 998;56:646-9.

6. Arnone D, Patel A, Tan GM. The nosological significance of folie à deux: a review of the literature. Ann Gen Psychiatry. 2006;5:1 I.

7. Cordeiro Q, Corbett CE. Delusional parasitic infestation and folie a deux: case report. Arq Neuropsiquiatr. 2003;61:872-5.

\section{IndEXAÇÃO AO ISI THOMSON}

A Sociedade Brasileira de Pneumologia e Tisiologia (SBPT) parabeniza a AMB pela inclusão, a partir de dezembro, da RAMB (Revista da Associação Médica Brasileira) no ISI Thomson, uma das mais importantes instituições de gerenciamento de periódicos científicos indexados do mundo.

Sabemos do esforço necessário para editar uma publicação desse nível e gostaríamos de estender os cumprimentos à equipe de editores, revisores, autores è̀ diretoria da $A M B$, que desde a criação da revista, em 1958, fazem da RAMB um instrumento de divulgação da ciência médica no Brasil.

Antônio Carlos Lemos
Presidente da Sociepade Brasileira de Pneumologia Presidente da Sociedade Brasileira de Pneumologia e Tisiologia 